\title{
Age-related decline in RACK-1 expression in human leukocytes is correlated to plasma levels of dehydroepiandrosterone
}

\author{
Emanuela Corsini, ${ }^{*, 1,2}$ Marco Racchi, ${ }^{\dagger, 2}$ Elena Sinforiani, ${ }^{\ddagger}$ Laura Lucchi, ${ }^{*}$ Barbara Viviani, ${ }^{*}$ \\ Gian Enrico Rovati, ${ }^{\S}$ Stefano Govoni, ${ }^{\dagger}$ Corrado L. Galli, ${ }^{*}$ and Marina Marinovich ${ }^{\star}$ \\ Laboratories of *Toxicology and ${ }^{\S}$ Signal Transduction, Department of Pharmacological Sciences, \\ University of Milan, Italy; ${ }^{\dagger}$ Department of Experimental and Applied Pharmacology, \\ University of Pavia, Italy; and ${ }^{\ddagger}$ IRCCS Fondazione C. Mondino, Pavia, Italy
}

\begin{abstract}
Aging is associated with remodeling of the immune system, contributing to increased incidence of infections, autoimmune diseases, and cancer among the elderly. Alterations in several signal transduction pathways have been reported to play an important role in immunosenescence. We show that peripheral blood leukocytes obtained from old donors ( $\geq 65$ years) have a significantly reduced expression of receptor for activated C kinase 1 (RACK-1), a protein required for protein kinase $\mathrm{C}$ (PKC)- $\beta$ signaling, as compared with young donors ( $\leq 40$ years), both in males and females. The decline in RACK-1 immunoboth in reactivity was age-related (Spearman correlation, $r=-0.278, P=0.012)$. All leukocyte subpopulations, namely lympho-monocytes, granulocytes, and $B$ and $T$ cells, showed a similar defect. We also observed a direct correlation between circulating dehydroepiandrosterone (DHEA) and RACK-1 expression in leukocytes (Spearman correlation, $\mathbf{r}=0.388, P=0.001)$. Furthermore, in vitro treatment with DHEA resulted in increased RACK-1 expression in leukocytes and lymphocyte proliferation, confirming the role of this hormone in the modulation of its expression and immune functions. A relevant consequence of RACK-1-reduced expression was the observation that release of tumor necrosis factor $\alpha$ following lipopolysaccharide challenge and mitogen-induced lymphocye proliferation, which involves PKC- $\beta$ activation, was significantly reduced in elderly subjects. Overall, our findings contribute to the understanding of the complex process of immunosenescence and identify age-related loss in immunological responses as partially associated with decreased RACK-1 expression. J. Leukoc. Biol. 77: 247-256; 2005.
\end{abstract}

Key Words: signal transduction $\cdot$ protein kinase $C \cdot$ immunosenescence $\cdot$ aging $\cdot$ cytokines

\section{INTRODUCTION}

The immune system is less able to cope with infectious disease during aging than earlier in life. Age-related changes in the immune system contribute to the increased incidence and severity of infections and possibly incidence of cancer among the elderly [1, 2]. Many studies have established that ageassociated immune decline is characterized by a decrease in humoral and cellular responses [3]. Many factors contribute to immunosenescence, including stem-cell defects, thymus involution, aging of resting immune cells, replicative senescence of clonally expanding cells as a result of erosion of telomere ends, defects in antigen-presenting cells, dysfunction in several signal transduction pathways, and dysregulation of the cytokine network [4-6].

We have recently demonstrated $[7,8]$ that the age-associated decline in rat immune function reflects an impaired protein kinase $\mathrm{C}$ (PKC) signal-transduction pathway and in particular, is related to a defective PKC-anchoring system. PKC is a family of at least 12 phospholipid-dependent, serine-threonine kinases involved in the signal transduction of hormones, neurotransmitters, and cytokines [9]. It mediates essential cellular signals required for activation, proliferation, differentiation, and survival of immune cells [10]. Activation of PKC results in redistribution (translocation) of the enzyme from the cytosol to membrane compartments for exerting its function [9]. This process is believed to be mediated by a family of proteins, receptors for activated C kinase (RACKs) [11]. One such protein, RACK-1, a $36-\mathrm{kDa}$ protein cloned from rat brain, is the best-characterized member of the RACK family; it preferentially interacts with PKC- $\beta$. RACK-1 modulates PKC activity by stabilizing its active conformation $[12,13]$. Other proteins, such as rat synaptic vesicle-specific p65 protein, phospholipase $\mathrm{C} \gamma$ (PLC $\gamma), \mathrm{PLC}_{-} \mathrm{A}_{2}$, and annexin, can bind to RACK-1 via a sequence similar to the $\mathrm{C} 2$ domain of $\mathrm{PKC}$, suggesting that RACK-1 may play a critical role in anchoring a range of proteins to the membrane and may integrate signaling pathways with different physiological functions [14]. The cDNA encoding RACK-1-like proteins has been identified from numerous organisms [15]. The expression of RACK-1

\footnotetext{
${ }^{1}$ Correspondence: Laboratory of Toxicology, Department of Pharmacological Sciences, University of Milan, Via Balzaretti 9, 20133 Milan, Italy. E-mail: emanuela.corsini@unimi.it

2 These authors contributed equally to this work.

Received May 4, 2004; accepted October 18, 2004; doi: 10.1189/ jlb.0504268.
} 
protein is variable in different organisms or different developmental stages. In mouse, RACK-1 is highly expressed in embryonic brain, but its expression decreases variably in different areas of the brain after postnatal development [16]. In rats, we demonstrated a development-associated increase in the expression of PCK- $\beta$ II and RACK-1, which correlated with the maturation of alveolar macrophage functional responses in rats at 2, 4, and 12 weeks of age [17]. By the age of 12 weeks, young adult rats possess fully matured alveolar macrophages with respect to their ability to respond to stimuli.

Concerning aging of the immune system, we have shown that a deficit in RACK-1, in the absence of differences in the expression of total PKC isoforms, underlies defective PKC activation and functional immune impairment in aged rats [7, 8]. Defective PKC activation with aging has also been reported by several authors in human monocytes $[18,19]$ and in human T lymphocytes [20, 21], and $\sim 50 \%$ of elderly subjects has significant reduction in PKC activity in B cells [22]. Agerelated impairment of the translocation of PKC is likely to underlie downstream defects in the activation of immune responses in vitro, as diminished generation of cytotoxic effectors, lower production of some cytokines, and reduced proliferative responses, and in vivo, as diminished response to vaccination and increased susceptibility to infections. It is now emerging that individual isoforms of PKC may exert specific functions in maintaining proper lymphocyte activation and tolerance. Mice homozygous for a target disruption of the gene encoding the PKC- $\beta \mathrm{I}$ and PKC- $\beta$ II isoforms develop an immunodeficiency characterized by impaired humoral immune response [23]. Similarly, mature T lymphocytes in PKC- $\theta-$ deficient mice exhibit defects in $\mathrm{T}$ cell antigen receptor-induced proliferation and reduced T-dependent responses [24]. In contrast, mice deficient in the $\delta$ isoform of PKC exhibit $\mathrm{B}$ cell hyperactivation, which leads to autoimmunity [25], demonstrating the critical and complex role for specific PKC isoforms in B and T cells functions.

We previously demonstrated that dehydroepiandrosterone (DHEA) treatment restores the age-decreased level of RACK-1 and immune deficits in rats, indicating that the age-related loss in immunological responses, linked to defective pathways of signal transduction, are under hormonal control and can be restored by appropriate replacement therapy [8]. In human, DHEA and its sulfate (DHEAS), the most abundantly secreted adrenal steroids, are known to increase throughout childhood and puberty and then to decrease in old age [26]. Following the peak by the third decade of life, its level declines steadily by $\sim 2 \%$ per year in males and females. It is important to mention that rodent adrenals lack the enzyme necessary to synthesize C-19 steroids and therefore, do not contribute to plasma levels of androstenedione and DHEA [27]. The average plasma level of DHEA in rodent is $0.6 \mathrm{ng} / \mathrm{ml}$, at least 10 times less than the average concentration in men [28]. Nevertheless, a decrease with age of DHEAS in rodents can be observed as well: we observed in 21-month-old rats a $50 \%$ reduction in plasma level of DHEAS, a stable marker of circulating DHEA levels [8]. Reduced secretion of DHEA during aging has been related to a series of age-associated conditions [29,30], including several lines of evidence, which indicate that DHEA and its metabolites are potent regulators of the immune response [31, 32].
Substantial data from animal studies have demonstrated a stimulatory effect of DHEA on immune function. For example, we demonstrated in vitro and in vivo that DHEA can restore lipopolysaccharide (LPS)-induced tumor necrosis factor $\alpha$ $(\mathrm{TNF}-\alpha)$ production in macrophages and in vivo mitogeninduced splenocyte proliferation [8]; May et al. [33] demonstrated that DHEA administration reversed corticosteroid and stress-induced inhibition of immune function, Loria et al. [34] showed that its administration has a protective effect against systemic Coxsackie virus and Herpes simplex type 2 encephalitis, and Daynes et al. [35] found that it can enhance interleukin (IL)-2 production by activated murine T cells. However, too little is known about the effects of DHEA supplementation on the human immune system, and it is still premature to relate these findings to routine clinical applications. In a small clinical trial, it has been demonstrated that orally administered DHEA $(50 \mathrm{mg} /$ daily) to age-advanced men with low serum DHEAS safely activated several immune functions within 2-20 weeks of treatment, including B and T cells mitogenic response and phytohemagglutinin (PHA)-induced IL-2 production, suggesting potential therapeutic benefits of DHEA supplementation in immunodeficient states [36].

Given the increasing proportion of elderly people worldwide, a better understanding of the causes and mechanisms of immunosenescence is crucial to identify whether prevention might be beneficial to enhance quality of life and to reduce the cost of medical care in old age. We therefore investigated RACK-1 expression in human peripheral blood leukocytes and the role of DHEA in an age-associated decrease in RACK-1. Accordingly, the present study was designed to determine if an age-related decline in RACK-1 expression was present and whether it would be correlated with circulating DHEA and paralleled by functional significance in humans.

\section{MATERIALS AND METHODS}

\section{Chemicals}

LPS from Escherichia coli serotype 0127:B8 and DHEA were obtained from Sigma Chemical Co. (St. Louis, MO), antibodies against RACK-1 from Transduction Laboratories (Affinity, Nottingham, UK), and anti-human $\beta$-actin from Sigma Chemical Co. Electrophoresis reagents were from Bio-Rad (Richmond, CA). All reagents were purchased at the highest purity available.

\section{Study protocol}

In this study, a total of 84 subjects living in the same geographical area of Northern Italy were recruited. These subjects included 20 elderly subject (age $71.8 \pm 0.8$ years, range $65-78 ; \geq 65$ years) and 64 subjects (age $39.7 \pm 1.4$ years, range $23-63 ;<65$ years). The $<65$ years group was further divided in two subgroups: a young adult $\leq 40$ years $(n=36$, mean \pm SEM, $32.2 \pm 1.0$ years $)$ and adult $41-64$ years old $(n=20$, mean \pm SEM, $50.5 \pm 1.6$ years $)$. All subjects signed an informed consent and were selected according to the guidelines of the Italian Health authorities and to the Declaration of Helsinki principles. Criteria for exclusion were abnormal laboratory values, medication known to affect the immune system, i.e., steroids and nonsteroideal, anti-inflammatory drugs, or patients suffering from malignancies, inflammations, and infections. Blood samples $(5 \mathrm{ml})$ were taken by venous puncture with sodium citrate 0.5 $\mathrm{M}$ as anticoagulant. Sodium citrate was chosen instead of heparin or EDTA as anticoagulant, as functional assays were performed using the whole blood assay, heparin may be contaminated with endotoxin, and EDTA interferes with cell activation. 
To investigate the in vitro effect of DHEA on RACK-1 expression, whole blood was washed three times with sterile phosphate-buffered saline, and the packed cells were reconstituted to the original volume with RPMI without phenol red (Sigma Chemical Co.) supplemented with 10\% charcoal-stripped, heat-inactivated calf serum (Sigma Chemical Co.). Diluted, washed blood (1:10) was then incubated for $24 \mathrm{~h}$ in the presence or absence of DHEA (15 $\mathrm{ng} / \mathrm{ml}$ ) or dimethyl sulfoxide as vehicle control. Cell homogenates were prepared for Western blot analysis as described below, and for mitogen-stimulated proliferation or cytokine release, diluted whole blood was then incubated in the presence or absence of PHA $1.2 \mu \mathrm{g} / \mathrm{ml}$ or $10 \mathrm{ng} / \mathrm{ml}$ phorbol myristate acetate (PMA) plus $100 \mathrm{ng} / \mathrm{ml}$ ionomycin or LPS $(1 \mu \mathrm{g} / \mathrm{ml})$ as described below.

To investigate the role of PKC- $\beta$ in LPS-induced cytokine production, diluted whole blood was cultured for $2 \mathrm{~h}$ in the presence or absence of a selective cell-permeable inhibitor of PKC- $\beta$ (PKC- $\beta$ pseudosubstrate, cat. no. 1792, Tocris, Avonmouth, UK). Then, LPS $0.1 \mu \mathrm{g} / \mathrm{ml}$ was added for $24 \mathrm{~h}$. Cytokine release in conditioned media was evaluated by commercially available enzyme-linked immunosorbent assay (ELISA) kits. The concentration of inhibitor used was not cytotoxic, as assessed by lactate dehydrogenase leakage in conditioned media (data not shown).

\section{Animals}

Young (3 months) and old (18 months) Sprague-Dawley male rats were purchased from Charles River (Calco, Italy). All animal care procedures were in accordance with the Italian Guidelines for Care and Use of Experimental Animals. Blood samples were taken by cardiac puncture with sodium citrate $0.5 \mathrm{M}$ as anticoagulant.

\section{Western blot analysis}

For RACK-1 and $\beta$-actin expression in leukocytes, $1.0 \mathrm{ml}$ blood was treated with ammonium chloride to remove red cells, and then the remaining leukocytes were lysed in $100 \mu \mathrm{l}$ homogenization buffer $(50 \mathrm{mM}$ Tris, $150 \mathrm{mM} \mathrm{NaCl}$, $5 \mathrm{mM}$ EDTA, pH 7.5, 0.5\% Triton X-100, $50 \mu \mathrm{M}$ phenylmethylsulfonyl fluoride, $2 \mu \mathrm{g} / \mathrm{mL}$ aprotinin, $1 \mu \mathrm{g} / \mathrm{mL}$ pepstatin, and $1 \mu \mathrm{g} / \mathrm{mL}$ leupeptin) and denatured for $10 \mathrm{~min}$ at $100^{\circ} \mathrm{C}$ [37]. For enrichment in lympho-monocytes, these cells were separated from granulocytes using a density gradient. Blood was diluted (1:3) with Hanks' balanced saline solution and layered on top of a tube containing lymphocyte separation medium (Gibco-BRL, Paisley, UK). After centrifugation at $2400 \mathrm{rpm}$ for $30 \mathrm{~min}$, the lympho-monocytes were recovered at the interface of the medium and Ficoll, centrifuged and lysed in $50 \mu \mathrm{l}$ homogenization buffer, and the pellet, containing red cells and granulocytes, was treated with ammonium chloride to remove red cells, and then the remaining granulocytes were lysed in $50 \mu$ l homogenization buffer. B and T lymphocytes were enriched using RosetteSep ${ }^{\mathrm{TM}}$ from StemCell Technologies Inc. (Vancouver, BC, Canada) from whole blood obtained from young and old donors $(n=4)$. The RosetteSep ${ }^{\mathrm{TM}}$ consists of a cocktail of patented, reagentcomplexed, tetrameric antibody. The cocktail targets a variety of unwanted cells and cross-links them to red blood cells present in the sample forming rosettes. The desiderated (unrosetted) cells are then collected as a centrifuged population from a Ficoll gradient. With this method, a 97\% enrichment in $\mathrm{CD}^{+}$cells and a $81 \%$ enrichment in $\mathrm{CD}^{+} 9^{+}$are obtained. After separation, the enriched populations were lysed in $50 \mu$ l homogenization buffer and prepared for Western blot analysis as described above. The protein content of the cell lysate was measured using a commercial kit (Bio-Rad). The cell proteins $(30 \mu \mathrm{g})$ were electrophoresed into a $12 \%$ sodium dodecyl sulfatepolyacrylamide gel under reducing conditions. The proteins were then transferred to a polyvinylidene difluoride membrane (Amersham, Little Chalfont, UK). The different proteins were visualized using RACK-1 (1:2500) and $\beta$-actin (1:5000) primary antibodies and developed using enhanced chemiluminescence (Amersham). The image of the immunoblotting was acquired with a Nikon charged-coupled device video camera module. The optical density of the bands was calculated and analyzed by means of the Image 1.47 program for digital image processing (Wayne Rasband, Research Service Branch, National Institutes of Mental Health, National Institutes of Health, Bethesda, MD).

\section{Assay for DHEA}

The levels of DHEA in human blood were determined by a commercially available enzyme immunoassay (Assay Design, Inc., Ann Arbor, MI) following the supplier's instructions. The limit of detection of the assay was $2.9 \mathrm{pg} / \mathrm{ml}$. Results are expressed as $\mathrm{ng} / \mathrm{ml}$.

\section{Lymphocyte subpopulations}

Peripheral blood $(50 \mu \mathrm{l})$ was stained with appropriate concentration of fluorescein- or phycoerythrin-conjugated monoclonal antibodies $(\mathrm{mAb})$ against CD3, CD4, CD8, CD19, CD25, and CD56/CD16 (Becton Dickinson, San Jose, CA) following the supplier's instructions. Flow cytometric analysis was performed in accordance with standard procedures on FACScan flow cytometry. Results are expressed as percentage or as absolute number of positive cells.

\section{Mitogen-stimulated proliferation assay}

Functional assays were performed using whole blood, added with sodium citrate as anticoagulants. Blood was diluted 1:10 with cell-culture medium RPMI 1640 (Sigma Chemical Co.) containing $2 \mathrm{mM} \mathrm{L-glutamine,} 0.1 \mathrm{mg} / \mathrm{ml}$ streptomycin, $100 \mathrm{IU} / \mathrm{ml}$ penicillin, as described previously [38]. Microcultures for the evaluation of mitotic response were set up in triplicates with 150 $\mu l$ diluted whole blood in 96-well plates in medium alone or in the presence of the following mitogenic stimuli: anti-CD3 $\mathrm{mAb}$ at a final concentration of 25 $\mathrm{ng} / \mathrm{ml}$ (Sigma Chemical Co.), PHA (Invitrogen, Paisley, UK) $1.2 \mu \mathrm{g} / \mathrm{ml}$ and 10 $\mathrm{ng} / \mathrm{ml}$ PMA (Sigma Chemical Co.), plus $100 \mathrm{ng} / \mathrm{ml}$ ionomycin (Sigma Chemical Co.). Cells were cultured for $96 \mathrm{~h}$ at $37^{\circ} \mathrm{C}$ in a humidified $5 \% \mathrm{CO}_{2}$ incubator and were pulsed during the final $18 \mathrm{~h}$ with $1 \mu \mathrm{Ci} /$ well ${ }^{3} \mathrm{H}$-thymidine (Amersham). Cells were harvested using a cell harvester (Dynatech, PBI, Milan, Italy), and the uptake of ${ }^{3} \mathrm{H}$-thymidine was measured in a scintillation counter (Packard, Meriden, CO). Results are expressed as stimulation index (S.I.), calculated as follows: S.I. $=\mathrm{cpm}$ mitogen $/ \mathrm{cpm}$ medium alone.

\section{Cytokine production}

For the evaluation of cytokine production, cultures were set up in open $12 \times$ 75 polypropilene reaction tubes (Falcon, Oxnard, CA) containing $1 \mathrm{ml}$ 1:10 diluted whole blood in medium alone or in the presence of LPS at a final concentration of $1 \mu \mathrm{g} / \mathrm{ml}$. Cells were incubated for $24 \mathrm{~h}$ at $37^{\circ} \mathrm{C}$ in a humidified $5 \% \mathrm{CO}_{2}$ incubator. Cell-free supernatants obtained by centrifugation at 1200 rpm for 5 min were stored at $-20^{\circ} \mathrm{C}$ until measurement. Cytokine production was assessed by ELISA using a commercially available kit (PharMingen, San Diego, CA). Results are expressed in $\mathrm{pg} / \mathrm{m}$ for TNF- $\alpha$ and $\mathrm{ng} / \mathrm{ml}$ for IL-8.

\section{Statistical analysis}

Data are expressed as mean \pm SEM. Statistical analysis was performed using GraphPad InStat Version 3.0a for Macintosh (GraphPad Software, San Diego, CA). Statistical differences were determined using the unpaired $t$-test or a multiple comparison test as indicated in the legends. Spearman correlation was used to analyze the correlation among RACK-1, age, and DHEA. Effects were designated significant if $P \leq 0.05$.

\section{RESULTS}

\section{Aging is associated with a progressive decline in RACK-1 expression in human leukocytes}

We have previously demonstrated that aging is associated with a progressive decrease in RACK-1 expression in rat macrophages and splenocytes obtained from outbred rats $[7,8]$ and that this defect correlates with a decrease in PKC-dependent immune functions. The purpose of this study was to investigate whether a similar defect was also associated with human immunosenescence. Before starting the human study, RACK-1 immunoreactivity was evaluated in peripheral blood leukocytes obtained from young (3 months) and old (18 months) rats. To control protein loading and to normalize RACK-1 expression, we evaluated $\beta$-actin immunoreactivity. As shown in Figure 1A, a statistically significant decrease in RACK-1 expression was observed, indicating that in rats, the previously identified 
defect in macrophages and splenocytes is also detectable in blood. RACK-1 immunoreactivity was then evaluated by Western blot analysis of human peripheral blood leukocyte homogenate, obtained from healthy old ( $\geq 65$ years) and young adult ( $\leq 40$ years) donors. As shown in Figure 1B, a significant decrease in RACK-1 expression was also observed in leukocytes obtained from old individuals in comparison with young donors with a reduction of $37.5 \pm 2.0 \%$ of RACK-1 immunoreactivity $(P=0.0005)$. The decline in RACK-1 immunoreactivity with age was observed in leukocytes obtained from female and male donors without significant differences among genders (Table 1).

We then evaluated the correlation between the decline in RACK-1 immunoreactivity and aging, including the data of RACK-1 expression in blood leukocytes obtained from all donors enrolled in the study. We found that RACK-1 expression progressively declines with age as shown in Figure 2, reporting the levels of RACK-1 plotted against the respective ages (Spearman correlation, $\mathrm{r}=-0.278$, and $P=0.012$ ).

As the antibody against RACK-1 used lacks adequate specificity, its use for flow cytofluorimetric analysis is precluded. Thus, to investigate the contribution of leukocyte subpopulations in RACK-1 immunoreactivity, different strategies were followed. First, lympho-monocytes were separated from gran-
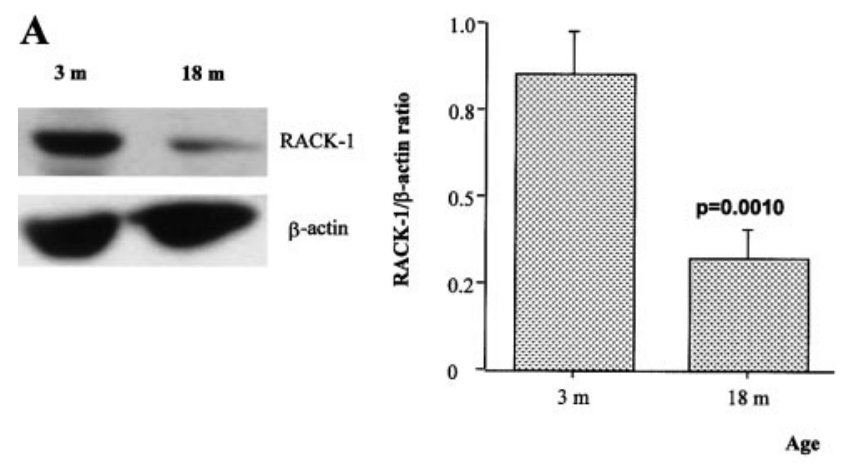

\section{B}
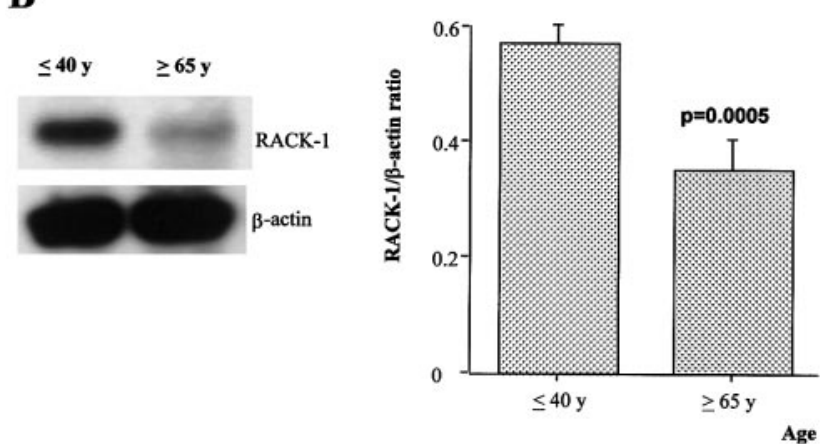

Fig. 1. Decreased RACK-1 immunoreactivity in peripheral blood leukocytes obtained from young and old individuals. (Left panels) Reported, representative Western blot analysis of RACK-1 and as control for protein loading, $\beta$-actin immunoreactivity in peripheral blood leukocyte homogenate obtained from young (3 months) and old (18 months) male rats (A) and human healthy donors $\leq 40$ years old and $\geq 65$ years old (B). (Right panels) The histograms show the quantification of RACK-1/ $\beta$-actin ratio by densitometric analysis. Each value represents the mean \pm SEM of five rats (A) and 36 donors for the group $\leq 40$ years and 20 for the group $\geq 65$ years (B). Statistical analysis has been performed by unpaired $t$-test. The $P$ value is reported in the figure.
TABLE 1. RACK-1 Immunoreactivity in Leukocytes Obtained from Female and Male Donors

\begin{tabular}{|c|c|}
\hline Donors & RACK- $1 / \beta$-actin ratio \\
\hline 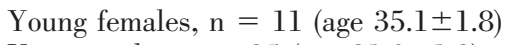 & $0.63 \pm 0.06$ \\
\hline Young males, $\mathrm{n}=25$ (age $31.0 \pm 1.2)$ & $0.54 \pm 0.04$ \\
\hline Old females, $\mathrm{n} \pm 7$ (age $72.7 \pm 1.0$ ) & $0.36 \pm 0.06^{*}$ \\
\hline Old males, $\mathrm{n}=13($ age $70.7 \pm 1.4)$ & $0.34 \pm 0.07 *$ \\
\hline
\end{tabular}

Values are mean \pm SEM. Column two reports the ratio RACK-1/ $\beta$-actin in leukocyte homogenates individually obtained and analyzed from young $(<40$ years) and old ( $\geq 65$ years) female and male healthy donors. Statistical analysis was performed by Bonferroni multiple comparison test. $* P<0.05$ versus young donors.

ulocytes using a density gradient, and second, B and T lymphocytes were enriched using RosetteSep ${ }^{\mathrm{TM}}$ from blood obtained from young and old donors $(n=4)$. As reported in Figure 3, a statistically significant reduction with aging in RACK-1 expression was observed in all leukocyte subpopulations investigated, indicating that the decrease in RACK-1 expression with aging reflects a defect common to all leukocytes. Thus, the results obtained from whole blood, even if crude, are representative of a defect associated with immunosenescence.

\section{Serum levels of DHEA correlate with RACK-1 expression}

We previously demonstrated that age-related loss in functional responses linked to PKC signal transduction defective pathway is partially under hormonal control and can be restored in rats by DHEA supplementation [8]. We speculated that a hormonal change (i.e., decrease in DHEA) in the cell environment associated with aging may be responsible for the loss in RACK-1 expression.

We observed (Fig. 4) that aging, as expected, was significantly correlated with a progressive decline in the plasma level

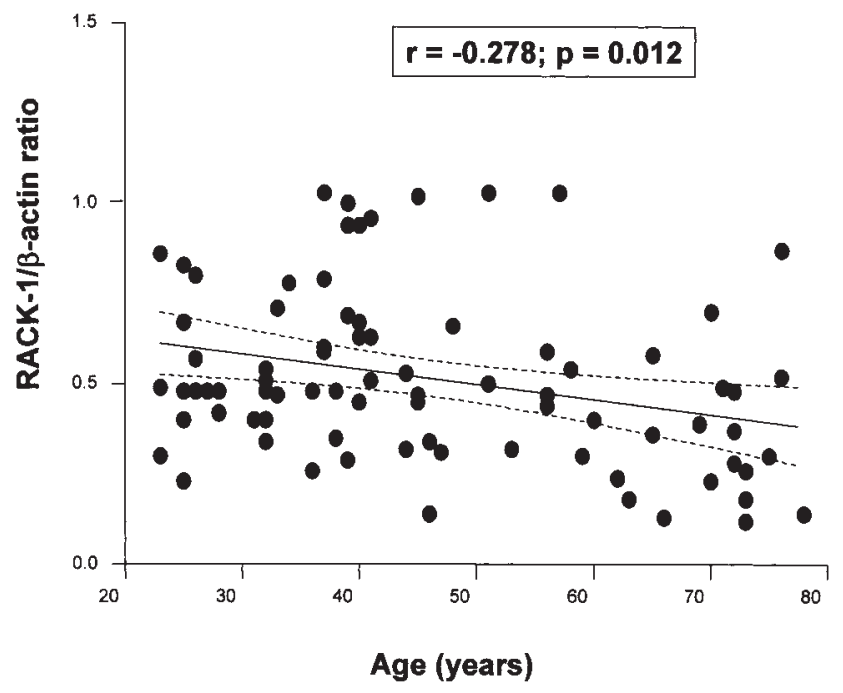

Fig. 2. Correlation between age and RACK-1/ $\beta$-actin ratio in human peripheral blood leukocytes. Correlation analysis of data was performed by Spearman correlation. The correlation coefficient, $\mathrm{r}$, and $P$ values are reported in the figure. Each dot represents a donor $(n=84)$. 


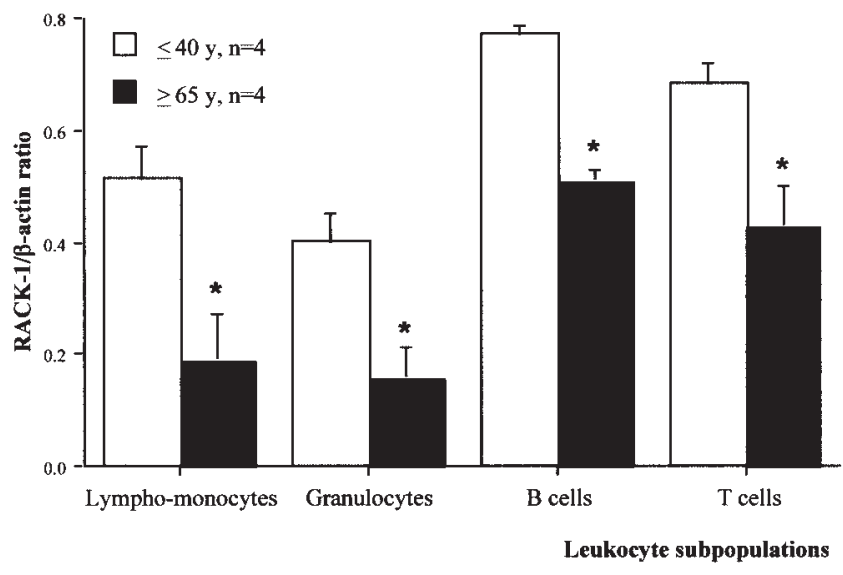

Fig. 3. RACK-1/ $\beta$-actin immunoreactivity in leukocyte subpopulation. Cell homogenates from lympho-monocytes, granulocytes, and $\mathrm{T}$ and $\mathrm{B}$ cells separated from blood obtained from young $(\leq 40$ years, $n=4)$ and old donors $(\geq 65$ years, $n=4$ ) were analyzed by Western blot analysis for RACK- 1 and $\beta$-actin immunoreactivity. Each value represents the mean \pm SEM of four donors. Statistical analysis was performed by unpaired $t$-test, and ${ }^{*}, P<0.05$, versus RACK- $1 / \beta$-actin ratio in young donors.

of DHEA (Spearman correlation, $\mathrm{r}=0.468, P=0.001$ ). It is interesting that in spite of a relatively low correlation coefficient, we observed a statistically significant correlation between RACK-1 expression in leukocytes and plasma level of DHEA (Spearman correlation, $\mathrm{r}=0.388, P=0.001 ;$ Fig. 5). To further support the role of DHEA on RACK-1 expression, the effect of a physiologically relevant concentration of DHEA (15 $\mathrm{ng} / \mathrm{ml}$ ) was evaluated in washed whole blood obtained from six donors of different ages. As shown in Figure 6A, treatment with DHEA for $24 \mathrm{~h}$ resulted in an increase in RACK-1 immunoreactivity in all donors tested compared with the expression of RACK-1 in vehicle-treated blood. In all tested samples, the expression of RACK-1 at least doubled (range from $+102 \%$ to $+350 \%$ ) following DHEA treatment, independently from the age of the donor. In another study, washed whole blood obtained from old individuals was treated in the

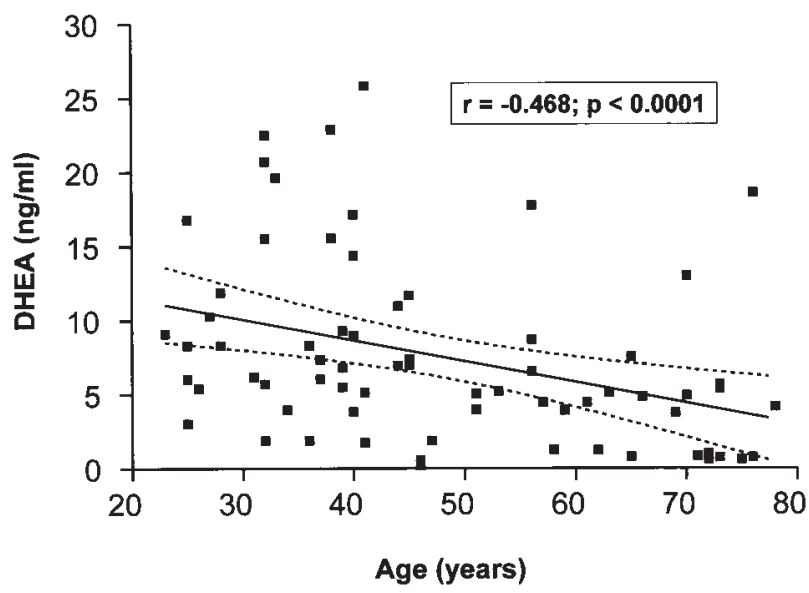

Fig. 4. Correlation between age and plasma level of DHEA in the humans enrolled into the study. Correlation analysis of data was performed by Spearman correlation. The correlation coefficient, $\mathrm{r}$, and $P$ values are reported in the figure. Each dot represents a donor $(n=84)$.

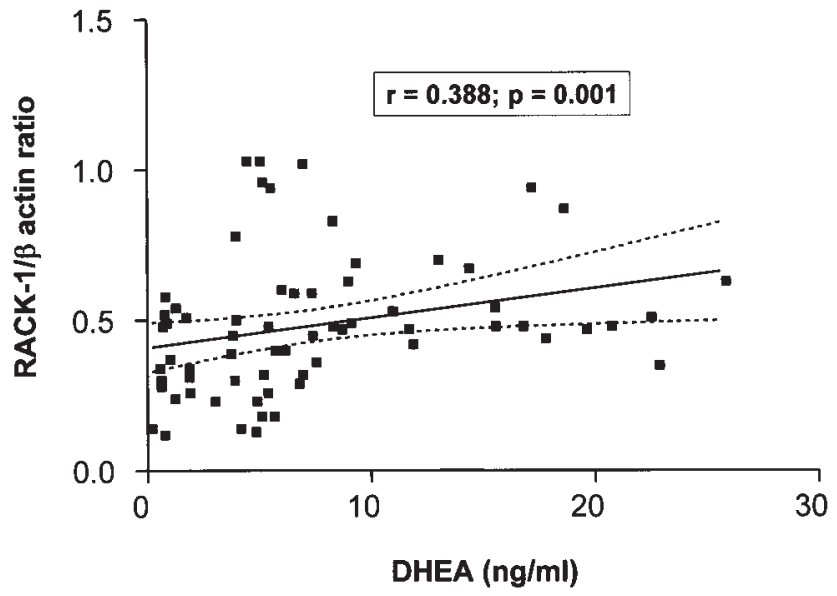

Fig. 5. Age-related correlation between plasma level of DHEA and RACK$1 / \beta$-actin ratio in human peripheral blood leukocytes. Correlation analysis of data was performed by Spearman correlation. The correlation coefficient, r, and $P$ values are reported in the figure.

presence or absence of DHEA for $24 \mathrm{~h}$ and then stimulated with PHA and phorbol ester plus ionomycin to assess lymphocyte proliferation. As shown in Figure 6B, in vitro treatment with DHEA resulted in increased mitogen-induced cell proliferation in all subjects (range from $+26 \%$ to $+176 \%$ for PHA; from $+40 \%$ to $114 \%$ for phorbol ester plus ionomycin), confirming the immuno-stimulatory properties of DHEA. These in vitro data are consistent with data obtained by Khorram et al. [36] in elderly men, who reported that in vivo supplementation with DHEA resulted in a restoration of mitogen-induced lymphocyte proliferation. The addition of the selective inhibitor of PKC- $\beta$ significantly reduced PHA and phorbol ester plus ionomycin-induced cell proliferation and prevented DHEA increased proliferation. From a 70-year-old donor, the S.I. after PHA was 80.8 in control cells, it was 103.0 in the presence of DHEA, and it was reduced to 48.4 in control cells treated with the PKC- $\beta$ inhibitor and 80.5 in cells treated with DHEA and the PKC- $\beta$ inhibitor. Similarly, after PMA plus ionomycin, the S.I. was 82.7 in control cells, 97.2 in the presence of DHEA, 55.7 in control cells treated with the PKC- $\beta$ inhibitor, and 67.9 in cells treated with DHEA and the PKC- $\beta$ inhibitor, indicating that PKC- $\beta$ is indeed involved in mitogen-induced cell proliferation.

Relative to TNF- $\alpha$ production, we have previously demonstrated that DHEA can restore age-associated, defective TNF- $\alpha$ production in response to LPS in rat macrophages [8]. In humans, the experiments in vitro are complicated by the fact that to perform hormonal treatment, we need to wash away the autologous serum, and cells have to be cultured in charcoalstripped serum. In these conditions, cells are probably lacking the presence of essential elements for an optimal response to LPS (i.e., the LPS-binding protein). An example of such effect can be given by some details of an experiment performed on the same sample of blood from an old donor. When such sample is simply diluted, and cells are exposed to their serum, the TNF- $\alpha$ production following LPS is $325 \mathrm{pg} / \mathrm{ml}$. When the same sample is washed and diluted to the same final volume in the presence of charcoal-stripped serum, the TNF- $\alpha$ produc- 
Fig. 6. DHEA up-regulated in vitro RACK-1 expression in peripheral blood leukocytes and stimulated mitogen-induced cell proliferation. (A, Inset) A representative Western blot analysis of RACK-1, and as control for protein loading, $\beta$-actin immunoreactivity in peripheral blood leukocyte homogenate obtained from a 70-year-old female donor is reported following $24 \mathrm{~h}$ incubation in the presence or absence of DHEA $(15 \mathrm{ng} / \mathrm{ml})$. Data are reported that were obtained from six healthy donors. F, Female; M, male; y, years. (B) Mitogeninduced proliferative response. Washed whole blood obtained from old donors was treated for $24 \mathrm{~h}$ in the presence or absence of DHEA $(15 \mathrm{ng} / \mathrm{ml})$; then, PHA $1.2 \mu \mathrm{g} / \mathrm{ml}$ or $10 \mathrm{ng} / \mathrm{ml}$ PMA plus 100 $\mathrm{ng} / \mathrm{ml}$ ionomycin was added. Results are expressed as S.I.

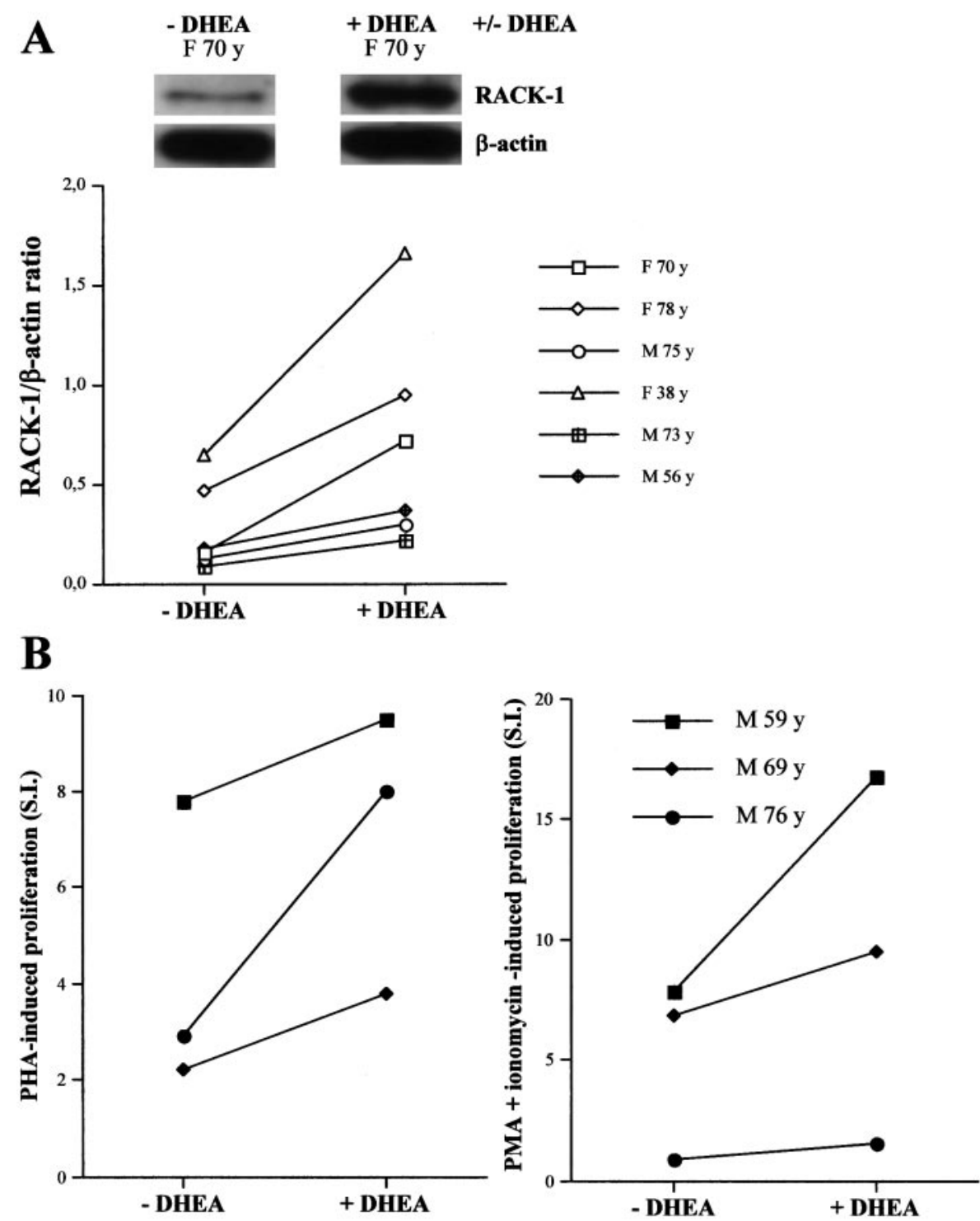

tion following LPS drops to $73 \mathrm{pg} / \mathrm{ml}$. For the same sample, DHEA treatment (made in charcoal-stripped serum) brings TNF- $\alpha$ production after LPS to $110 \mathrm{pg} / \mathrm{ml}$. In the presence of these limitations, we nevertheless observed that treatment with DHEA (15 ng/ml) on washed whole blood from three young donors and two old donors produced a significant increase in LPS-induced TNF- $\alpha$ release, ranging from $+37 \%$ to $+53 \%$ in young donors and from $+50 \%$ to $+86 \%$ in old donors. Also in this case, the addition of the selective inhibitor of PKC- $\beta$ prevented the stimulatory effect of DHEA on LPS-induced TNF- $\alpha$ release: DHEA induced a $+58 \pm 23 \%$ increase in TNF- $\alpha$ release, which was reduced to $+3 \pm 28 \%$ in the presence of the PKC- $\beta$ inhibitor, further supporting the link between DHEA/RACK-1 and PKC- $\beta$.

\section{Decreased functional response in leukocytes of old donors}

Aging is associated with a functional decline of the immune system [39]. We initially performed assays on whole blood from young and old donors $(n=6)$ to study proliferative responses to anti-CD3 antibody, PHA, and phorbol ester plus ionomycin to assess congruity of our aged population with literature data. An extremely significant reduction in mitogen-induced lymphocyte proliferation was observed in aged donors in comparison with young donors, consistent with literature data (Table 2) [5, 6, 40].

The decrease in lymphocyte proliferation is unlikely to be a result of change in the absolute number or percentage of $B$ and T cells. Fluorescence-activated cell sorter analysis performed on blood from young and old subjects showed $73.8 \pm 1.8 \%$ versus $73.2 \pm 1.7 \%$ in $\mathrm{CD}^{+} / \mathrm{CD} 45^{+}$cells in young versus old donors (absolute number $1271 \pm 91.8$ vs. $1421 \pm 203 \mathrm{cells} / \mu \mathrm{l}$ ) and $10.6 \pm 0.8 \%$ versus $11.7 \pm 1.4 \%$ in $\mathrm{CD} 19^{+} / \mathrm{CD} 45^{+}$cells (absolute number $185.4 \pm 17.7$ vs. $278 \pm 37.2 \mathrm{cells} / \mu \mathrm{l}$ ). This is consistent with Stulnig et al. [41], who reported that the number and relative percentage of lymphocytes $\mathrm{CD}^{+}$and $\mathrm{CD} 19^{+}$ or monocytes were similar in healthy young and old subjects.

In rats, we have shown that aging was associated with a progressive decline in the ability of alveolar macrophage to release TNF- $\alpha$ in response to LPS as a result of reduced RACK-1 expression [7]. In our population, we found that stimulation with LPS in whole blood assays resulted in signif- 
TABLE 2. Proliferative Response to Mitogens in Peripheral Blood Leukocytes Obtained from Young and Old Donors

\begin{tabular}{lr}
\hline \hline Donors & \multicolumn{1}{c}{ S.I. } \\
\hline Young, $n=6$ (age $29.0 \pm 2.6):$ & \\
Anti-CD3 $25 \mathrm{ng} / \mathrm{ml}$ & $104.2 \pm 21.2$ \\
PHA $1.2 \mu \mathrm{gl} / \mathrm{ml}$ PMA $10 \mathrm{ng} / \mathrm{ml}$ plus $100 \mathrm{ng} / \mathrm{ml}$ ionomycin & $396.8 \pm 56.8$ \\
Old, $n=7$ (age $77.2 \pm 3.2):$ & $267.3 \pm 73.0$ \\
Anti-CD3 $25 \mathrm{ng} / \mathrm{ml}$ & $3.5 \pm 1.0^{* *}$ \\
PHA $1.2 \mu \mathrm{mg} / \mathrm{ml}$ & $42.4 \pm 9.2^{* *}$ \\
PMA $10 \mathrm{ng} / \mathrm{ml}$ plus $100 \mathrm{ng} / \mathrm{ml}$ ionomycin & $22.1 \pm 6.0^{* *}$ \\
\hline
\end{tabular}

Diluted whole blood from donors of different ages was incubated for $96 \mathrm{~h}$ in medium alone or with optimal concentrations of different mitogenic stimuli. Cell proliferation was evaluated by ${ }^{3} \mathrm{H}$-thymidine incorporation. Results are expressed as S.I. Background level of counts in unstimulated cells did not differ significantly between young and old donors $(340+116 \mathrm{cpm}$, minimum 126, median 214, maximum 1016 for young donors and 455+106 cpm, minimum 207, median 368, maximum 817 for old donors). Values are means \pm SEM. Statistical analysis was performed by unpaired $t$-test. $* * P<$ 0.01 versus young donors.

icantly reduced levels of TNF- $\alpha$ released by cells from old donors as compared with young donors, as assessed by a specific ELISA (Fig. 7A). The decrease in LPS-induced TNF- $\alpha$ release was age-related, as a progressive decline was observed in the middle-aged donors (41-64 years old). The spontaneous release of this cytokine was below the limit of detection in all groups. In contrast, the release of IL-8, another proinflammatory cytokine, was not affected by aging. A similar release in spontaneous and LPS-stimulated IL-8 release was observed in all donors (Fig. 7B). This observation may be a result of a differential involvement of PKC- $\beta$ in LPS-induced TNF- $\alpha$ and IL-8 production. As shown in Table 3, treatment with a selective inhibitor of PKC- $\beta$ in human whole blood significantly reduced LPS-induced TNF- $\alpha$ (from $732 \pm 277$
TABLE 3. Effect of a Selective, Cell-Permeable Inhibitor of PKC- $\beta$ (PKC- $\beta$ Pseudosubstrate) on LPS-Induced TNF- $\alpha$ and IL-8 Release from Human Leukocytes

\begin{tabular}{lcc}
\hline \hline Treatment & TNF- $\alpha(\mathrm{pg} / \mathrm{ml})$ & IL-8 $(\mathrm{pg} / \mathrm{ml})$ \\
\hline Control & $2 \pm 3$ & $168 \pm 186$ \\
PKC- $\beta$ inhibitor $5 \mu \mathrm{M}$ & $3 \pm 5$ & $97 \pm 68$ \\
LPS $0.1 \mu \mathrm{g} / \mathrm{ml}$ & $732 \pm 277^{* *}$ & $6696 \pm 790^{* *}$ \\
PKC- $\beta$ inhibitor + LPS & $263 \pm 117^{* *, \S \S}$ & $6450 \pm 797^{* *}$ \\
\hline
\end{tabular}

Diluted whole blood obtained from four young donors was incubated for $2 \mathrm{~h}$ in the presence or absence of the PKC- $\beta$ inhibitor, and then LPS was added where indicated for $24 \mathrm{~h}$. Values are means \pm SD. Statistical analysis was performed by Tukey-Kramer multiple comparison test. $* * P<0.01$ versus relative control and $\S \S P<0.01$ versus LPS-treated cells.

$\mathrm{pg} / \mathrm{ml}$ to $263 \pm 117 \mathrm{pg} / \mathrm{ml}$ ), and no change in IL-8 production was observed, indicating that PKC- $\beta$ isoform is involved in the pathway leading to TNF- $\alpha$ production but not in LPS-induced IL-8 production. This effect was observed in young and old donors. The fact that the selective inhibitor of PKC- $\beta$ did not completely abrogate LPS-induced TNF- $\alpha$ production may suggest that the PKC- $\beta$ signaling pathway does not control TNF- $\alpha$ production exclusively.

\section{DISCUSSION}

Altogether, the data suggest a cascade of events leading to an age-associated, defective activity of PKC signal transduction machinery involved in the regulation of immune functions. In particular, in spite of a large, interindividual variability, a positive correlation between plasma level of DHEA and RACK-1 immunoreactivity was found, suggesting an important role of this hormone in maintaining RACK-1 expression and
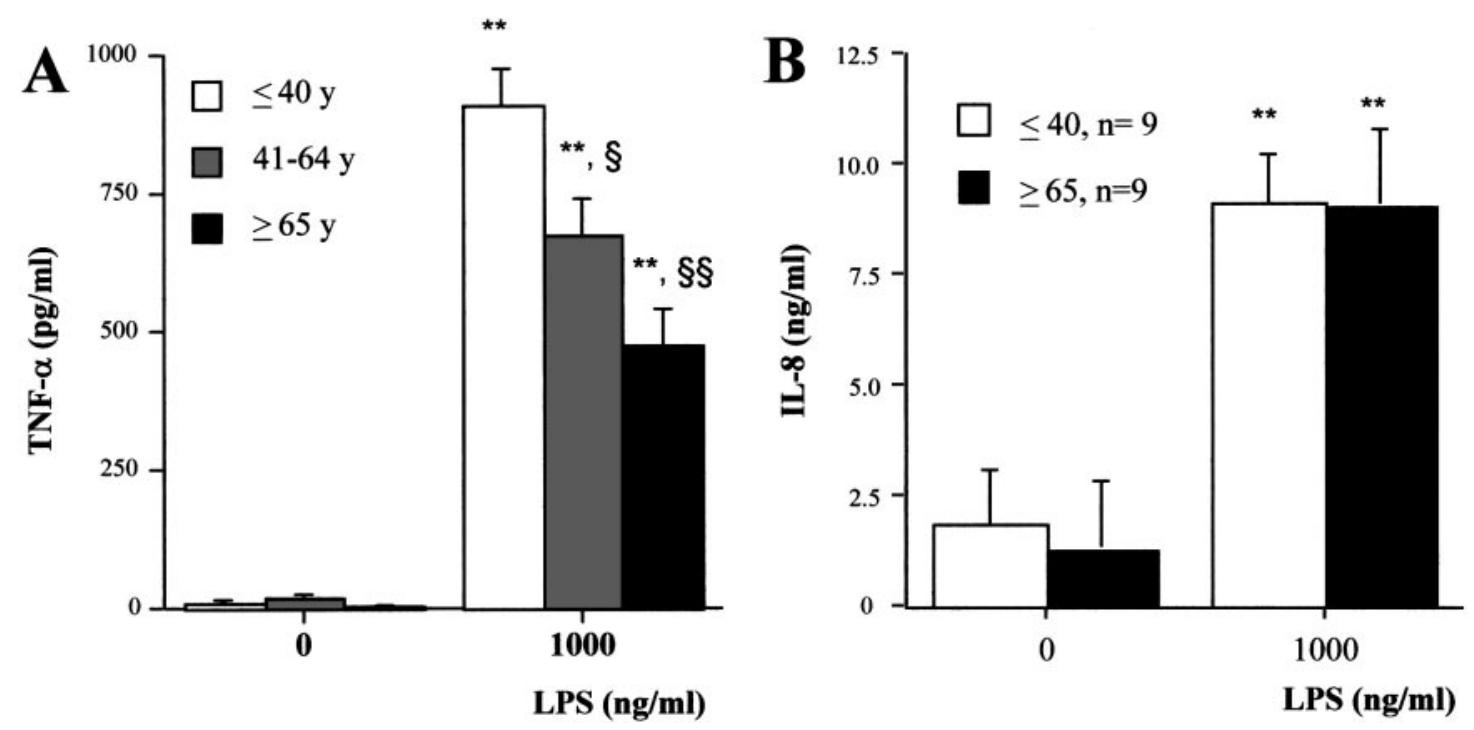

Fig. 7. Decreased TNF- $\alpha$ release in LPS-stimulated whole blood obtained from old donors. Whole blood obtained from healthy donors of different ages was diluted 1:10 and incubated for $24 \mathrm{~h}$ in the presence or absence of LPS (1000 ng/ml). TNF- $\alpha$ (A) and IL-8 (B) release was assessed by specific ELISA. Each value represents the mean \pm SEM, $\mathrm{n}=$ number of donors reported in the figure. Statistical analysis was performed by Tukey multiple comparison test, and $* *, P<0.01$, versus spontaneous release $(0 \mathrm{LPS})$ and $\S, P<0.05$, and $\S \S, P<0.01$, versus $\leq 40$-year group. 
PKC- $\beta$-mediated immune activation in human leukocytes. The decreased DHEA levels appear to drive a defect in leukocyte expression of RACK-1, in turn, leading to impaired PKC functions and consequent defective, functional, immunological responses. If true, the understanding of such mechanism of immunoregulation in the aged immune system may lead to effective treatment for age-related human diseases in the future.

In addition, our previous research in experimental animals demonstrated that not only the immune system but also the nervous system responded to DHEA supplementation with increased RACK-1 expression [42, 43], supporting a generalized role of this hormone in maintaining PKC-dependent functional responses. It is indeed emerging that the defect in PKC activation with aging reflects changes in signals that recruit PKC to the membrane rather than alterations in enzyme levels or intrinsic functional capacity [20, 44].

The mechanism of action of DHEA is still controversial, and further studies are necessary to address this point. At present, we cannot directly establish whether DHEA or its metabolites selectively increase the transcription of RACK-1 through a direct interaction with the androgen receptor or other downstream transcription factors or by activation of a specific plasma membrane receptor, whose physiological functions have not been characterized yet [44, 45]. With the use of flutamide, an androgen receptor antagonist, we could demonstrate in rat macrophages that DHEA-induced RACK-1 expression was prevented, suggesting that DHEA or more likely, its metabolites act through the androgen receptor. However, in the $5^{\prime}$-flanking region, at least within $800 \mathrm{bp}$ upstream of the putative promoter region of the porcine RACK-1 gene, no androgen receptor transcriptional binding sites have been described [46]. It has been demonstrated recently that nuclear factor (NF)- $\kappa \mathrm{B}$ regulates the mouse RACK-1 gene expression, and specific inhibitors of NF- $\mathrm{KB}$ activation decrease RACK-1 expression in PC12 cells [47]. In preliminary experiments, we found that treatment of alveolar macrophages obtained from old rats with DHEA $(3 \mathrm{ng} / \mathrm{ml})$ for 30 min resulted in p65 nuclear translocation and inhibitor of $\mathrm{\kappa B}$ degradation, indicating NF- $\kappa$ B activation, which in turn, may account for DHEAinduced RACK-1 neosynthesis, a putative mechanism that awaits further characterization.

A speculation can be made that hormonal changes in the cell environment associated with aging, in particular, the agerelated decline in the levels of DHEA, are likely to contribute to the loss in RACK-1 expression in leukocytes. In rats, a support to such speculation may be derived from the data that indicate that newly generated cells in the bone marrow of old rats have a similar level of RACK-1 as bone marrow cells isolated from young rats. It is during the maturation, differentiation, and distribution in blood and secondary lymphoid organs that immune cells, influenced by the hormonal milieu, start to exhibit a reduction in the levels of RACK-1 in aged rats (data not shown). The reduction with aging in RACK-1 expression was observed in all leukocyte subpopulations investigated, indicating that it may reflect a defect common to all leukocytes. Thus, the results reported from whole blood, even if crude, are indeed representative of a defect associated with immunosenescence. It is also possible that cells may express an aging- related change in the hormonal sensitivity, although in such case, it would be more difficult to explain the differences among young and old individuals as well as the response of the cells from aged donors to the hormone. Certainly, the defect cannot be ascribed to gross changes in the number and subtype composition of the leukocyte population as shown here and consistent with the literature [41].

Using the whole blood assay, we found a decrease with aging in the proliferative response to mitogens and a decrease in LPS-induced TNF- $\alpha$ release in the old donors, and no changes in LPS-induced or spontaneous IL-8 production were detected. The whole blood assay was used, as it requires less blood, cells are maintained in their natural environment, and the risk of loss of minor lymphocyte subsets through density gradient is eliminated. The decrease in the proliferative responses is consistent with data published in the literature [6], and conflicting results have been published concerning the effect of aging on proinflammatory cytokine production, with data reporting increase [48, 49], no change, or decrease production [50]. This is likely to be a result of different methodologies used (i.e., whole blood vs. purified cells), incubation time, stimuli, and different leukocyte subset contribution among others. Indeed, after stimulation of whole blood samples from healthy elderly with LPS [51], IL-1 and IL-6 secretion were significantly elevated, but stimulation of their peripheral blood mononuclear cells showed lower amounts of cytokines compared with peripheral blood mononuclear cells of healthy young donors.

Overall, cytokines are essential for proper antigen presentation, activation of lymphocytes, and elimination of invading microorganisms; thus, the alteration of the cytokine network is believed to play a role in the remodeling of the immune system in old age [52]. In this paper, we measured LPS-induced TNF- $\alpha$ and IL-8 production. TNF- $\alpha$ is one of the major cytokines produced during an infection. A decrease in the ability of cells to produce this cytokine is likely to contribute to increased susceptibility to infections. IL-8 is an inflammatory cytokine, which functions mainly as a neutrophil chemoattractant, and activating factor.

In whole blood, most cell types are able to produce many cytokines. B and T cells and monocytes are the main producers of TNF- $\alpha$, and IL-8 production is mainly a result of neutrophils, although also monocytes and $\mathrm{B}$ and $\mathrm{T}$ cells can produce it. Using the selective, cell-permeable inhibitor of PKC- $\beta$, the specific kinase isoform interacting with RACK-1, we could demonstrate that only LPS-induced TNF- $\alpha$ release could be significantly modulated by the PKC- $\beta$ inhibitor, and the release of IL-8 was not affected, providing additional evidence that specific PKC isoforms may be differentially involved in the pathways leading to cytokine production. However, the fact that the selective inhibitor of PKC- $\beta$ did not completely abrogate LPS-induced TNF- $\alpha$ production may suggest that the PKC- $\beta$ signaling pathway does not control TNF- $\alpha$ production exclusively.

Overall, this paper contributes to the understanding of the complex process of aging of the immune system and identifies a progressive decline in RACK-1 expression with aging, related to a decline in DHEA level. The identification of changes 
in the immune cells will allow the elaboration of better strategies for the prevention of infective diseases in the elderly [53]. Even in the presence of intrinsic defects in peripheral lymphocytes of elderly subjects, it is possible that these may be overcome by measures that are relatively easy in principle (i.e., to test whether hormonal treatment can restore immune functions declined with aging); yet, these principles need to be clearly tested in appropriate clinical protocols and settings with particular caution because of the unresolved problems related to the risk of cancer associated with this type of treatment.

\section{ACKNOWLEDGMENTS}

This work was partially supported by FIRST funds from the University of Milan to C. L. G., by the Center for Toxicological Risk Assessment of the University of Milan, and by a grant from the Ministry of Health Italy (Progetto Finalizzato Alzheimer) to E. S.

\section{REFERENCES}

1. Emmerling, P., Hof, H., Finger, H. (1979) Age-related defense against infection with intracellular pathogens. Gerontology 25, 327-336.

2. Newell, G. R., Spitz, M. R., Sider, J. G. (1989) Cancer and age. Semin. Oncol. 16, 3-9.

3. Tarazona, R., Solana, R., Ouyang, Q., Pawelec, G. (2002) Basic biology and clinical impact of immunosenescence. Exp. Gerontol. 37, 183-189.

4. Doria, G., Biozzi, G., Mouton, D., Covelli, V. (1997) Genetic control of immune responsiveness, ageing and tumor incidence. Mech. Ageing Dev. 96, 1-13.

5. Hirokawa, K. (1999) Age-related changes of signal transduction in T cells. Exp. Gerontol. 34, 7-18.

6. Pawelec, G., Barnett, Y., Forsey, R., Frasca, D., Globerson, A., Mclead, J., Caruso, C., Franceschi, C., Fulop, T., Gupta, S., Mariani, E., Moccheggiani, E., Solana, R. (2002) T cells and aging, January 2002 update. Front. Biosci. 7, D1056-D1183.

7. Corsini, E., Battaini, F., Lucchi, L., Marinovich, M., Racchi, M., Govoni, S., Galli, C. L. (1999) A defective protein kinase C anchoring system underlying age-associated impairment in $\mathrm{TNF}-\alpha$ production in rat macrophages. J. Immunol. 163, 3468-3473.

8. Corsini, E., Lucchi, L., Meroni, M., Racchi, M., Solerte, B., Fioravanti, M., Viviani, B., Marinovich, M., Govoni, S., Galli, C. L. (2002) In vivo dehydroepiandrosterone restores age-associated defects in protein kinase $\mathrm{C}$ signal transduction pathway and related functional responses. J. Immunol. 168, 1753-1758.

9. Nishizuka, Y. (1995) Protein kinase C and lipid signaling for sustained cellular responses. FASEB J. 9, 484-496.

10. Su, T. T., Guo, B., Rawlings, D. J. (2002) Emerging of PKC isoforms in immune cell function. Mol. Interv. 2, 141-144.

11. Mochly-Rosen, D., Khaner, H., Lopez, J. (1991) Identification of intracellular receptor proteins for activated protein kinase C. Proc. Natl. Acad. Sci. USA 88, 3997-4000.

12. Ron, D., Mochly-Rosen, D. (1994) Agonists and antagonists of protein kinase $\mathrm{C}$ function, derived from its binding proteins. J. Biol. Chem. 269, 21395-21398.

13. Ron, D., Luo, J., Mochly-Rosen, D. (1995) C2 region-derived peptides inhibit translocation and function of $\beta$ protein kinase $\mathrm{C}$ in vivo. J. Biol. Chem. 270, 24180-24187.

14. McCahill, A., Warwicker, J., Bolger, G. B., Houslay, M. D., Yarwood, S. J. (2002) The RACK-1 scaffold protein: a dynamic cog in cell response mechanisms. Mol. Pharmacol. 62, 1261-1273.

15. Neer, E. J., Schymidt, C. J., Nambudripad, R., Smith, T. F. (1994) The ancient regulatory-protein family of WD-repeat proteins. Nature $\mathbf{3 7 1}$, 297-300.

16. Imai, Y., Suzuki, Y., Tohyama, M., Wanaka, A., Takagi, T. (1994) Cloning and expression of a neural differentiation-associated gene, p205, in the embryonal carcinoma cell line P19 and in the developing mouse. Brain Res. Mol. Brain Res. 24, 313-319.

17. Corsini, E., Viviani, B., Lucchi, L., Marinovich, M., Racchi, M., Galli, C. L. (2001) Ontogenesis of protein kinase C $\beta I I$ and its anchoring protein RACK-1 in the maturation of alveolar macrophage functional responses. Immunol. Lett. 76, 89-93.

18. McLachlan, J. A., Serkin, C. D., Morrey, K. M., Bakouche, O. (1995) Immunological functions of aged monocytes. Pathobiology 63, 148-159.

19. Delpedro, A. D., Barjavel, M. J., Mamdouh, Z., Fauve, S., Bakouche, O. (1998) Signal transduction in LPS-activated aged and young monocytes. J. Interferon Cytokine Res. 18, 429-437.

20. Fulop, T., Leblanc, C., Lacombe, G., Dupuis, G. (1995) Cellular distribution of protein kinase $\mathrm{C}$ isozymes in CD3-mediated stimulation of human T lymphocytes with aging. FEBS Lett. 375, 69-74.

21. Miller, R. A. (2000) Effect of aging on T lymphocyte activation. Vaccine 18, 1654-1660.

22. Whisler, R. L., Grants, I. S. (1993) Age-related alterations in the activation and expression of phosphotyrosine and protein kinase $\mathrm{C}$ among human B cells. Mech. Ageing Dev. 71, 31-46.

23. Leitges, M., Schmedt, C., Guinamard, R., Dovoust, J., Schaal, S., Stabel, S., Tarakhovsky, A. (1996) Immunodeficiency in protein kinase C $\beta$-deficient mice. Science 273, 788-791.

24. Sun, Z., Arendt, C. W., Ellmeier, W., Schaeffer, E. M., Sunshine, M. J., Gandhi, L., Annes, J., Petrzilka, D., Kupfer, A., Schwartzberg, P. L., Littman, D. R. (2000) PKC- $\theta$ is required for TCR-induced NF-кB activation in mature but not immature T lymphocytes. Nature 404, 402-407.

25. Miyamoto, A., Nakayama, K., Imaki, H., Hirose, S., Jiang, Y., Abe, M., Tsukiyama, T., Nagahama, H., Ohno, S., Hatakeyama, S., Nakayama, K. I. (2002) Increased proliferation of B cells and auto-immune in mice lacking protein kinase C $\delta$. Nature 416, 865-869.

26. Vermeulen, A. (1995) Dehydroepiandrosterone sulfate and ageing. Ann. N. Y. Acad. Sci. 774, 121-127.

27. Van Weerden, W. M., Bierings, H. G., van Steenbrugge, G. J., de Jong, F. H., Scroder, F. H. (1992) Adrenal glands of mouse and rat do not synthesize androgens. Life Sci. 50, 857-861.

28. Cutler, G. B., Glenn, M., Bush, M., Hodgen, G. D., Graham, C. E., Loriaux, D. L. (1978) Adrenarche: a survey of rodents, domestic animals, and primates. Endocrinology 103, 2112-2118.

29. Ebeling, P., Koivisto, V. A. (1994) Physiological importance of dehydroepiandrosterone. Lancet 343, 1479-1481.

30. Shealy, C. N. (1995) A review of dehydroepiandrosterone. Integr. Physiol. Behav. Sci. 30, 308-313.

31. Loria, R. M., Padgett, D. A., Huynh, P. N. (1996) Regulation of the immune response by dehydroepiandrosterone and its metabolites. J. Endocrinol. 150, S209-S220.

32. Williams, J. R. (2000) The effects of dehydroepiandrosterone on carcinogenesis, obesity, the immune system, and ageing. Lipids 35, 325-331.

33. May, M., Holmes, E., Rogers, W., Poth, M. (1990) Protection from glucorticoid induced thymic involution by dehydroepiandrosterone. Life Sci. 46, 1627-1631.

34. Loria, R. M., Inge, T. H., Cook, S. S., Szaki, A. K., Regelson, W. (1988) Protection against acute lethal viral infection with the naïve steroid dehydroepiandrosterone (DHEA). J. Med. Virol. 26, 301-314.

35. Daynes, R. A., Dudley, D. J., Araneo, B. A. (1990) Regulation of murine lymphokine production in vivo. II. Dehydropeiandrosterone is a natural enhancer of interleukin-2 synthesis by helper T cells. Eur. J. Immunol. 20, 793-802.

36. Khorram, O., Vu, L., Yen, S. C. (1997) Activation of immune function by dehydroepiandrosterone (DHEA) in age-advanced men. J. Gerontol. A Biol. Sci. Med. Sci. 52, M1-M7.

37. Laemmli, V. K. (1970) Cleavage of structural proteins during the assembly of the head of bacteriophage T4. Nature 227, 680-685.

38. Kirchner, H., Kleinicke, C., Digel, W. (1982) A whole blood technique for testing production of human interferon by leukocytes. J. Immunol. Methods 48, 213-219.

39. Wick, G., Grubeck-Loebenstein, B. (1997) Primary and secondary alterations of immune reactivity in the elderly: impact of dietary factors and disease. Immunol. Rev. 160, 171-184.

40. Gupta, S. (1989) Membrane signal transduction in $\mathrm{T}$ cells in aging humans. Ann. N. Y. Acad. Sci. 568, 277-282.

41. Stulnig, T., Maczek, C., Bock, G., Majdic, O., Wick, G. (1995) Reference intervals for human peripheral blood lymphocyte subpopulations from healthy young and aged subjects. Int. Arch. Allergy Immunol. 108, 205-210.

42. Racchi, M., Govoni, S., Solerte, B. S., Galli, C. L., Corsini, E. (2001) Dehydroepiandrosterone and the relationship with aging and memory: a possible link with protein kinase $\mathrm{C}$ functional machinery. Brain Res. Brain Res. Rev. 37, 287-293. 
43. Racchi, M., Balduzzi, C., Corsini, E. (2003) Dehydroepiandrosterone (DHEA) and the aging brain: flipping a coin in the "fountain of youth". CNS Drug Rev. 9, 21-40.

44. Battaini, F., Pascale, A., Paoletti, R., Govoni, S. (1997) The role of anchoring protein RACK1 in PCK activation in the aging rat brain. Trends Neurosci. 20, 410-415.

45. Liu, D., Dillon, J. S. (2002) Dehydroepiandrosterone activates endothelial cell nitric oxide synthase by a specific plasma membrane receptor coupled to $\mathrm{G}_{\alpha 2,3}$. J. Biol. Chem. 277, 21379-21388.

46. Chou, Y. C., Chou, C. C., Chen, Y. K., Tsai, S., Hsieh, F. M. J., Liu, H. J., Hseu, T. H. (1999) Structure and genomic organization of porcine RACK1 gene. Biochim. Biophys. Acta 1489, 315-322.

47. Choi, D. S., Young, H., McMahon, T., Wang, D., Messing, R. O. (2003) The mouse RACK-1 gene is regulated by nuclear factor- $\mathrm{KB}$ and contributes to cell survival. Mol. Pharmacol. 64, 1541-1548.

48. Fagiolo, U., Cossarizza, A., Scala, E., Fanales-Belasio, E., Ortolani, C., Cozzi, E., Monti, D., Franceschi, C., Paganelli, R. (1993) Increased cytokine production in mononuclear cells of healthy elderly people. Eur. J. Immunol. 23, 2375-2378.

49. Clark, J. A., Peterson, T. C. (1994) Cytokine production and aging: overproduction of IL-8 in elderly males in responses to lipopolysaccharide. Mech. Ageing Dev. 77, 127-139.

50. Gon, Y., Hashimoto, S., Hayashi, S., Koura, T., Matsumoto, K., Horie, T. (1996) Lower serum concentration of cytokines in elderly patients with pneumonia and the impaired production of cytokines by peripheral blood monocytes in the elderly. Clin. Exp. Immunol. 106, 120126.

51. Gabriel, P., Cakman, I., Rink, L. (2002) Overproduction of monokines by leukocytes after stimulation with lipopolysaccharide in the elderly. Exp. Gerontol. 37, 235-247.

52. Doria, G., Frasca, D. (1997) Genes, immunity, and senescence: looking for a link. Immunol. Rev. 160, 159-170.

53. Beverley, P. C. L., Grubeck-Loebenstein, B. (2000) Is immune senescence reversible? Vaccine 18, 1721-1724. 